\title{
Political control and policy-making uncertainty in executive orders: the implementation of environmental justice policy
}

\author{
COLIN PROVOST \\ Department of Political Science/School of Public Policy, University College London, UK \\ E-mail: c.provost@ucl.ac.uk \\ BRIAN J. GERBER \\ College of Public Service and Community Solutions, Arizona State University, USA \\ E-mail: Brian.Gerber@asu.edu
}

\begin{abstract}
Environmental justice (EJ) has represented an important equity challenge in policymaking for decades. President Clinton's executive order (EO) 12898 in 1994 represented a significant federal action, requiring agencies to account for EJ issues in new rulemakings. We examine the impact of EO 12898 within the larger question of how EO are implemented in complex policymaking. We argue that presidential preferences will affect bureaucratic responsiveness and fire alarm oversight. However, EJ policy complexity produces uncertainty leading to bureaucratic risk aversion, constraining presidential efforts to steer policy. We utilise an original data set of nearly 2,000 final federal agency rules citing EO 12898 and find significant variation in its utilisation across administrations. Uncertainty over the nature of the order has an important influence on bureaucratic responsiveness. Our findings are instructive for the twin influences of political control and policy-making uncertainty and raise useful questions for future EJ and policy implementation research.
\end{abstract}

Key words: environmental justice, environmental policy, executive order, public administration, regulation, rulemaking

The concept of environmental justice (EJ) speaks to the challenge of ensuring fairness and equity for all citizens in public policymaking. Concerns over EJ are premised on the idea that vulnerability to environmental hazards exposure, such as air or water pollution or hazardous waste from industrial activities is not equally distributed across all members of a community; rather risks fall disproportionally on minority or lower income groups. Political advocates pursued EJ for years but no major federal action was taken until 1994, when President Clinton issued executive order (EO) 
12898 ("Federal Actions to Address Environmental Justice in Minority Populations and Low-Income Populations") (Cutter 1995). EO 12898 is designed to mitigate EJ problems by requiring agencies to consider the impact of new rules on environmental hazard exposure inequity, "to the greatest extent practicable and permitted by law ..." (EO 12898, Sections 1-101). Consequently, agencies must think carefully about how EJ considerations might be implemented. While EO 12898 does not sanction agencies for failing to consider EJ in rulemaking, the order puts in place institutional and administrative arrangements (e.g. the Interagency Working Group on Environmental Justice) to encourage the full consideration of EJ in rulemaking.

Presidents have many administrative tools to steer agency behaviour in their preferred direction (Wood and Waterman 1994; Mayer 1999; Kerwin 2003; Whitford 2005). At the same time, agencies may struggle with implementation due to uncertainty embedded in the policy-making process and in the scientific information surrounding environmental decisions (Whitford 2014; Noonan 2015; Shadbegian and Wolverton 2015). Here, we investigate the conflicting factors of political control and policymaking uncertainty over the only major federal policy effort on EJ: the implementation of EO 12898 in agency rulemaking.

In the United States (US), the president has a wide array of tools at his/her disposal to influence regulatory policy outputs and preferences over these regulatory actions have a partisan cast. Democratic presidents typically prefer more robust regulatory regimes while Republican presidents prefer a more business-friendly approach (Wood and Waterman 1994). Presidents can steer regulatory policy and administrative agency efforts through the use of political appointees (Nathan 1983; Moe 1985; Wood and Waterman 1994; Whitford 2005; Lewis 2008), EOs (Cooper 1986, 2002; Krause and Cohen 1997; Mayer 1999), agency reorganisation (Moe 1987; Wood and Waterman 1994) and through the review of new regulatory rules (McGarity 1991; Kerwin 2003). Given the high transaction costs of monitoring regulated entities and enforcing regulations, presidential actions can also facilitate modes of fire alarm oversight, whereby affected constituents bring regulatory violations to the attention of the president, Congress or federal agencies (e.g. McCubbins and Schwartz 1984). Depending on policy preferences and shifts in partisan control of the presidency, subsequent administrations may or may not honour existing patterns of bureaucratic action derived from such administrative tools and oversight mechanisms.

Further, the relative efficacy of executive political control and influence can be undermined by a lack of certainty in policymaking. Uncertainty about the information and science that feeds into particular policies can 
have an independent effect on agency outputs (Whitford 2014). Such uncertainty may be partly created by business interests during the rule-making process (Yackee and Yackee 2006; Wagner 2010), but it may also be due to a lack of strong scientific findings. Scientific uncertainty is important because federal agencies have considerable discretion in their day-to-day decisionmaking, generally. Producing new rules that rely on uncertain scientific information may result in adverse environmental or health impacts and can dramatically undermine an agency's reputation. Reputational costs can be damaging and may result in greater political oversight and less discretionary autonomy. Thus, agencies want to ensure that they make good decisions or, at the very least, decisions that are not bad (Carpenter 2002, 2004; Whitford 2014). When scientific information is consistently uncertain, it can produce risk aversion on the part of those bureaucrats tasked with making sense of such information.

Uncertainty in EJ scholarship also exists, as some studies have found clear racial and class-based disparities [United States General Accounting Office (US GAO) 1983; Commission for Racial Justice 1987; Bullard 1990, 1993; Been 1994, 1995; Goldman and Fitton 1994; Ringquist 1997], whereas others fail to find linkages to environmental hazards and claim that empirical findings are potentially unreliable due to faulty research designs (Anderton et al. 1994; US GAO 1995; Cutter et al. 1996; Oakes et al. 1996; Mitchell et al. 1999; Bowen and Wells 2002). Thus, there is enough conflict within the EJ literature to suggest that there is some uncertainty embedded within the relevant scientific information and data.

In this article, we examine the dual forces of political control and policymaking uncertainty. Under EO 12898, agencies are to consider a new rule's EJ impact, specifically whether the rule has positive impacts for EJ, whether it has no impact, or whether EJ issues are not relevant to the rule's content. We test hypotheses of political control and policy-making uncertainty to see how they affect the implementation of EJ policy across federal agencies from the start of EO 12898 through the end of President Obama's first term.

The analysis here offers three primary contributions to the academic literature on regulation and environmental policy broadly, including EJ issues more specifically. First, uncertainty in policy-making factors into studies of policy analysis more and more. Ambiguities in policy processes affect the ability of political principals to influence policy, and they also affect how agencies act in response to reputational concerns. Specifically, we show how the uncertainties in policymaking can interact to affect how rules and laws are written. We believe this particular contribution is important, as it makes our work generalisable beyond an American context. The data and institutions discussed in this article all emanate from the 
US, but the problems of environmental inequity, combined with uncertain data and science, are ubiquitous. Second, understanding how these factors play out is particularly important for those affected by EJ concerns. Studies that have scrutinised the implementation efficacy of EJ as a policy goal in the US, particularly since EO 12898 was written, have not been kind (e.g. Konisky 2015, 2016), while articulating some of the reasons for the failure of efforts aimed at EJ promotion. We build on this work by arguing that policy-making uncertainty has played a major role in undermining political attempts to successfully steer EJ in the right direction. And third, the analysis provides insight to the much broader issue of presidential policymaking by use of administrative tools such as EOs, especially in a technically complex and politically contentious domain such as environmental regulation. Much of the extant research on EOs examines the circumstances under which they are written (including volume of activity) or the content which they might contain (Cooper 1986, 2002; Krause and Cohen 1997; Mayer 1999). We build upon this work by examining the administrative implementation of such orders, thus providing a detailed look at how such orders actually affect policymaking.

The article proceeds as follows. First, we discuss the history of the American EJ movement. Second, we review the literatures on political control and uncertainty in policy-making processes, specifically examining the role of scientific information and bureaucratic institutions and their combined effects on administrative outputs. We then present a model to explain how agencies have utilised EO 12898 in federal rulemaking, using an original data set that codes for content all federal rules that cite EO 12898, written from 1994 through 2012. We discuss our findings in the light of the historical discussion and attempt to capture effects that may be difficult to demonstrate through quantitative methods alone. We then conclude and suggest further avenues of research on EJ.

\section{The origins and state of EJ}

The modern EJ movement began in Warren County, North Carolina in 1982. Four years earlier, a trucking company illegally dumped more than 30,000 tons of polychlorinated biphenyls-contaminated waste oil along North Carolina rural roads (Burwell and Luke 2007). Although the perpetrators of this act were convicted and imprisoned, state officials still had to decide how to dispose of the highly toxic waste. Ultimately, they chose the small, poor and largely African-American town of Afron within Warren County to dispose of the waste, a decision which generated large-scale protests. Although the waste was ultimately transferred to the dump in Warren County, the EJ movement was galvanised. 
Disparities in environmental impacts and in the enforcement of environmental regulation received more attention after the events in Warren County and after the United Church for Christ Commission for Racial Justice (1987) published a study indicating that race was a significant factor when deciding where to site toxic waste landfills. Despite the increased level of attention, very little happened in Congress in the years that followed (Konisky 2016). In response, President Clinton signed EO 12898 in 1994 which states that each federal agency "shall make achieving environmental justice part of its mission by identifying and addressing, as appropriate, disproportionately high and adverse human health or environmental effects of its programs, policies, and activities on minority populations and low-income populations" (EO 12898, Sections 1-101). The order provides general guidance for federal bureaucratic action, including efforts to foster nondiscrimination in federal programs and to give minority and low-income communities greater opportunities for participation and information access.

EO 12898 also creates an interagency working group comprised of the heads of several relevant executive departments and other federal agencies. ${ }^{1}$ The working group is tasked with helping identify potential EJ concerns, helping to coordinate the development of EJ strategies for federal agencies, ${ }^{2}$ and helping to coordinate research, data collection and scrutiny of relevant empirical evidence on EJ issues. Where practicable, agencies are to collect data such as race, economic status, and national origin to assess and compare human health risks and to share data. The working group is also tasked with reporting to the President on EO 12898's implementation. Thus, from a rule-making perspective, agencies must attempt to account for the impact that new rules have on EJ, whenever possible.

Since its inception in 1994, presidential attention to EO 12898 has varied. The Bush Administration sought to downplay the significance of race and ethnicity in agency rulemaking (O'Neil 2007; Salcido 2016), a development which caused the US Office of Inspector General (2004) and the GAO (2005) to rebuke the EPA for its failure to consider equity in its rulemaking.

1 The working group is chaired by the US Environmental Protection Agency (EPA) and includes the Departments of Defense, Health and Human Services, Housing and Urban Development, Labor, Agriculture, Transportation, Justice, Interior, Commerce, Energy, and several units within the Executive Office of the President. A precursor, the Environmental Equity Workgroup at EPA, had been created in 1990.

${ }^{2}$ Each agency submits an outline of its proposed EJ strategy to the working group for review, including specifying projects to address concerns found during the development of the strategy. Each agency must conduct its programs to ensure it is not excluding persons from participation, denying them of benefits or discriminating against them because of race, colour or natural origin. Agencies are prompted to assess multiple and cumulative hazard exposure if possible. Agency heads are responsible for ensuring compliance with EO 12898. 
The Obama Administration devoted considerable resources to dealing with environmental inequity, specifically creating a new interagency working group, whose participants all signed a memorandum of understanding, devoted to accomplishing the goals of EO 12898 (Kaswan 2013; Konisky 2015; Salcido 2016). This group was part of the larger programme "Plan EJ 2014" which signified a renewed effort to emphasise the importance of EJ in EPA activities. We seek to explain how these presidential initiatives have affected agency response to implementing EO 12898.

\section{Political control and EOs}

Early work on political control of the bureaucracy tended to focus on Congress and its oversight of federal regulatory agencies (e.g. Weingast and Moran 1983; McCubbins and Schwartz 1984). Subsequent research has focussed more on the role of the president in managing the federal bureaucracy. The role of political appointees selected to head agencies is paramount, as they shape the direction of federal agencies (Moe 1985; Wood and Waterman 1994; Lewis 2005, 2008, 2009; Whitford 2005). Presidents can also utilise a number of other important administrative tools, perhaps most notably the EO.

The EO has become increasingly important for presidents as a tool to exercise oversight over agency rulemaking. EOs are of interest because they signify binding direction for federal bureaucratic action (thereby being functionally similar to statutes), do not require congressional approval, and can sometimes represent profound policy change (see Mayer 2001; Cooper 2002). They are also used to steer the process of notice and comment rulemaking, specifically to influence the manner in which agencies evaluate rules and policies, looking in particular at the costs and benefits of new regulations. Since President Ford questioned whether regulations were a costly burden to the economy, each president thereafter has committed to varying levels of rule-making cost-benefit analysis. Reagan's EO 12291 laid down a stringent standard for measuring and articulating benefits, while President Clinton's EO 12886 articulated that agencies must perform $\mathrm{C} / \mathrm{B}$ analysis on economically significant or important rules. Thus, successive presidents - Bush and Obama as well - have used EOs to impose constraints and boundaries on the process of administrative rulemaking and shape the content of subsequently created rules.

EO 12898 is another such rule that reconfigures the means by which agencies evaluate the rules that they draft. It incorporates decision making on EJ issues into administrative rulemaking, as agencies are directed to consider the impact of the rule on EJ, although they may fail to show such consideration. If 12898 is considered, citations typically indicate whether the rule will have a positive (affirmative) impact on environmental 
inequity, whether it was considered and thought to have no impact or whether it was not a relevant consideration at all. Agencies under Democratic presidents are likely to pursue regulatory enforcement more aggressively (Wood and Waterman 1994). We therefore should expect that agencies under Democratic presidents would make more affirmative cites of EO 12898 when creating new rules than would Republican presidents.

H1: Affirmative citations of EO 12898 will increase during Democratic presidential administrations.

Presidents may also use more indirect means of policy influence, such as fire alarm oversight. The transaction costs of monitoring regulated entities and enforcing regulations can be quite high when dealing with heterogeneous industries across a vast population. Consequently, members of Congress and the presidency are reliant upon civil society and business to "pull the fire alarm" and indicate either when businesses are breaking the law or when agencies are not perceived to be appropriately implementing the law (McCubbins and Schwartz 1984). Additionally, fire alarm oversight may facilitate interest group influence over the bureaucracy, if Congress "hardwires" agencies to reflect the preferences of particular groups (McCubbins et al. 1987, 1989). Similarly, Congress may "stack the deck" by requiring administrative procedures which favour those same groups.

Affected interests or citizens can complain to congressional representatives or bring legal action against particular agencies. Businesses might sue agencies because they perceive regulations to be too onerous, while NGOs and other members of civil society are more likely to sue agencies for failing to implement regulations. EO 12898 does not afford individuals any explicit right of action, but under Title VI of the Civil Rights Act, individuals and groups can file formal complaints against state or local agencies for causing "disparate impacts" during the course of implementing EJ policy. These complaints are investigated by the overseeing federal agency, typically the EPA. If fire alarm oversight works, then we would expect responsiveness to an increase in Title VI complaints with more affirmative cites of EO 12898. However, responsiveness to fire alarms is also likely to be conditional upon the ideology of presidential administrations. That is, as Title VI complaints rise, affirmative rule citations should increase in Democratic administrations, but not necessarily in Republican ones.

H2a: Affirmative citations of EO 12898 will increase as Title VI complaints increase.

H2b: Affirmative citations of EO 12898 will increase as Title VI complaints increase, but only during Democratic presidential administrations. 
However, research subsequent to the work of McCubbins et al. (1987, 1989) has been less kind empirically to the notion of fire alarm oversight. For example, legislative staff and resources, not interest group presence, drive the existence of clean air consultation procedures in the states (Potoski 1999). Legislative resources - not consultation procedures - affect agency influence over policy (Potoski and Neal 2001) which suggests that fire alarm oversight does little to affect agency behaviour. Others have reached similar conclusions about this method of agency oversight (Spence 1997, 1999; Balla 1998). When we examine internal agency dynamics in policy implementation, there are additional reasons to be sceptical about the impact of fire alarm oversight and specifically, Title VI complaints. We address these elements of policy-making uncertainty in the next section.

\section{Policy-making uncertainty}

Agencies have high levels of discretion in decisionmaking in their daily activities, which revolve in part around maintaining an organisation's reputation and preventing decisions that negatively affect that reputation. Agencies have multiple audiences embedded in the world of business, government and civil society, and their reputations depend on making good decisions or at least, decisions that are not bad (Carpenter 2002, 2004). Agencies rely on their decision-making processes to keep their reputations intact and fend off political challenges as well. For example, Maor (2007) has demonstrated how political principals often undermine the independence of pharmaceutical regulators, but are not willing to interfere with the process of conducting clinical trials, which is considered to be the "gold standard" for pharmaceutical regulators.

The creation of new rules involves utilising available scientific and economic information in order to assess the rule's costs, benefits and broader impact. If information is highly uncertain, it makes it more difficult for agencies to produce rules that are grounded in sound decisionmaking (Whitford 2014). In such situations, agencies are more likely to avoid making positive and bold claims in new rules if the information underlying those claims is at all suspect. Consequently, risk aversion may set in amongst civil servants who are responsible for crafting such rules, as agencies attempt to do the least amount of damage possible, rather than strive for big gains in new rules.

Informational uncertainty is present in a number of ways at the intersection of administrative rulemaking and EJ. First, affirmatively citing EO 12898 means that the analysts involved are confident that the rule will bring benefits to local communities that mitigate environmental inequities, but measuring benefits in regulatory impact analyses is subjective, imprecise 
and therefore difficult (McGarity 1991). Data are often incomplete, unavailable or there may be questions about measurement, such as the value placed on human life or the value of preserving endangered species. Compounding this problem is the fact that agencies often have different valuations, as for example, they may fail to continually adjust for inflation in their benefit/value figures (Appelbaum 2011). Thus, measuring the benefits of polices designed to reduce the inequalities in environmental enforcement is difficult to do, partly because measuring benefits is exceedingly difficult to do.

Measuring the benefits of EJ for local communities is difficult for at least two other reasons. First, there is often significant uncertainty within scientific information and this is reflected in studies that attempt to detect the presence of environmental racism or injustice. A variety of studies have suggested linkages of disparate environmental risk exposure with race and/ or class (US GAO 1983; United Church for Christ Commission for Racial Justice 1987; Bullard 1990, 1993; Been 1994, 1995; Goldman and Fitton 1994; Ringquist 1997). Mohai and Bryant's (1992) review of empirical research on 21 types of environmental hazards found that most studies demonstrated statistically significant relationships with race and income. That conclusion was echoed in a similar review by Goldman (1993). However, Bowen and Wells (2002) charge that empirical findings in this area are mixed and potentially unreliable, due to faulty research designs. Skeptics of EJ also refer to competing empirical studies that do not find clear or consistent linkages of race and class with exposure to environmental hazards (Anderton et al. 1994; US GAO 1995; Oakes et al. 1996).

Sapat et al. (2002) suggest that traditional empirical analysis of EJ problems has often been limited by narrowly operationalised measures of environmental quality or total risk exposure. An additional and important concern raised by Sapat et al. is that the research focus of EJ empirical studies has frequently excluded salient dimensions of the policy-making process, such as the nature of public participation in land use planning. Consequently, progress towards a resolution between the two sides of the EJ debate has been slowed. A meta-analysis by Ringquist (2005) of 49 different studies on environmental inequities showed that environmental inequities do exist according to race, but not necessarily according to income class. Research by Grant et al. (2010) indicates that the presence or absence of environmental inequities depends very much on the type of facility in a given area, as well as the type of community affected by that facility. Finally, other recent research shows that enforcement of federal environmental laws tends to be weaker in low-income neighbourhoods (Konisky 2009a) and that changes in federal environmental policy during the 1990s had little effect on state enforcement of environmental laws 
(Konisky 2009b). Thus, progress has been made in establishing that there are environmental inequities, but uncertainty remains as to the magnitude and the precise conditions of such inequities.

Additionally, it may be difficult to know how new policy tools in administrative rules will affect conditions on the ground in different communities. This leads to another source of uncertainty which deals more with geography than science itself. Major environmental laws like the Clean Air Act and the Clean Water Act are designed to improve the overall state of air and water throughout the US, through relatively uniform, nationwide standards, while EJ issues are specific to particular places (Kaswan 2013; Noonan 2015). A number of scholars also argue that in order to identify the impact of agency actions, the analyst must have a baseline or counter-factual which would indicate how populations and environmental risks would be clustered, in the presence as well as the absence of the rule (Noonan 2008, 2015; Maguire and Sheriff 2011). Similarly, Shadbegian and Wolverton (2015) argue that to evaluate potentially different impacts according to race or income, the analyst needs comparison groups, a requirement sometimes made difficult by data that rely on inconsistent definitions of "minority" or "low income". This point is particularly important as EO 12898 stipulates that the EJ Working Group shall, "provide guidance to federal agencies for identifying disproportionately high and adverse human health or environmental effects on minority populations and lowincome populations" (EO 12898, Section 1-102). These points support the idea that agencies will find it challenging to affirmatively cite EO 12898 in new rulemakings and may fall back on weaker declarations of no discernible impact.

The combination of scientific and geographic uncertainty embedded in proposals potentially dealing with EJ issues make it difficult for agencies to affirmatively claim that new rules will mitigate concerns of environmental racism or injustice. Consequently, bureaucrats are more likely to be risk averse in these instances and avoid positive statements that appear to promise strong benefits for communities that are used to experiencing, or perceived to be experiencing high levels of environmental inequity. There is evidence of such risk aversion occurring with respect to rulemaking and citing EO 12898. Specifically, agencies that consider EJ issues are more likely to indicate that a rule will not make existing EJ issues worse, rather than claim significant improvements towards environmental injustice (Banzhaf 2011-2012).

Finally, policy-making uncertainty may also have an effect on enforcement related to fire alarm oversight. Under Title VI of the Civil Rights Act, individuals and groups can file formal complaints against state or local agencies for causing "disparate impacts", which are then referred to the federal agency in question, whose duty it is to investigate the complaint and make a final decision. If there is a sufficient level of uncertainty in the data and information used to generate new rules, agencies may be loath to raise expectations 
of local communities, fearing that if such expectations go unfulfilled, there will be a rise in Title VI complaints. For example, what is a "disparate impact"? This issue again brings us back to the uncertainty of information, data and science. It is often difficult to know whether a disparate impact is present and even more difficult to know if it was caused by a particular state or local agency. Thus, agencies may avoid affirmative citations of EO 12898, believing that such cites may create legal fodder for more complaints.

The structure of Title VI complaint investigation somewhat compounds the problem of uncertainty. Complaints dictate that federal agencies follow up with investigations of state or local agencies, yet federal agencies must work with state and local agencies to implement policies broadly across the nation. Federal agencies have incentives not to antagonise the state and local agencies with whom they have working relationships. Konisky and Teodoro (2016) find that government agencies violate regulations and face smaller penalties than do regulated businesses. Additionally, Kaswan writes, "the EPA may be reluctant to impose available remedies - like withholding federal funding - because of the perception that such remedies are overly draconian or unconstructive. Moreover, EPA may hesitate to interfere with state agency decision-making due to federalism concerns" (2013). Federal agencies may come to believe that affirmative citations of EO 12898 are likely to raise expectations of community and local groups and if EJ benefits are not delivered, then complaints about state and local agencies may be more likely and forthcoming. In order to deter such complaints from arising, agencies may be more likely to make risk averse statements about certain rules not creating further damage or harm, rather than making statements that boldly proclaim new benefits.

H3: Affirmative citations of EO 12898 will decrease as Title VI complaints increase.

With Hypotheses 2 and 3, we consider the potentially opposite roles that political control and policy-making uncertainty may play, as they generate different impacts of fire alarm oversight on rule citation. In the next section, we present our data and our research design.

\section{Research design}

We assess the impact of EO 12898 on agency behaviour by examining the scope and substantive nature of citations of EO 12898 in all final rules published in the US Federal Register for the period from February 1994 (when the order was issued) through December 2012. ${ }^{3}$ By covering the

\footnotetext{
${ }^{3}$ Rule data were collected for the same group of agencies that appear in the EJ Working Group mentioned in footnote 1: EPA, Departments of Defense, Health and Human Services,
} 
Clinton and Bush Administrations, as well as the first term of the Obama Administration, we observe significant variation in ideology and political values regarding EJ and equity. Under EO 12898, agencies are tasked with considering a new rule's potential impact on EJ, if such considerations are relevant to the rulemaking. However, this obligation is not necessarily powerful: an agency can cite the order but simply deem it irrelevant to the rule's content. Similarly, agencies may sometimes fail to cite the EO altogether, rather than cite it as irrelevant to the rule. Therefore, identifying the substantive nature of EO 12898 citations helps explain the actual impact of President Clinton's initiative to consider EJ. As a gauge of attention towards the $\mathrm{EJ}$ issue, we also measure the annual total number of rules produced by the relevant agencies, to observe the proportion of rules each year, containing EO 12898 cites. $^{4}$

Citations of EO 12898 in a rule-making action (for final rules) fall into one of six possible categories. The first category is an "affirmative" use of the order. This means that the final rule's language indicated that EO 12898 was specifically relevant to the final content of the rule and the action had beneficial EJ consequences. For example, in a 1998 rule-making action on drinking water ("Revision...to comply with the requirements of the Safe Drinking Water Act"), the EPA cited EO 12898 and went on to state: "The Agency believes that this rule has the potential to significantly reduce risks to children caused by inadequate drinking water and address environmental justice problems" (63 FR 157, 1998: 43833). A citation was also coded as affirmative if the rule indicated that EO 12898 specifically prompted other deliberative considerations germane to EJ, such as the creation of stakeholder meetings. ${ }^{5}$ For example, in another drinking water rule ("National primary drinking water regulations; radionuclides"), the EPA noted: "The Agency has considered environmental justicerelated issues concerning the potential impacts of this action and has consulted with minority and low-income stakeholders by convening a stakeholder meeting ... to address environmental justice issues" (65 FR 236, 2000: 76707). ${ }^{6}$

Housing and Urban Development, Labor, Agriculture, Transportation, Justice, Interior, Commerce and Energy. Our analysis only applies to citations of EO 12898 from federal agencies in rule-making procedures. It does not apply to the implementation of these rules at the subnational level, by state agencies or regional EPA offices.

${ }^{4}$ The aggregate counts of total rules for each agency were gathered through the US GAO's database of major and nonmajor rules. These data only go back as far as 1996, a fact reflected in the data in Table 2.

${ }^{5}$ A rule was also cited as having an affirmative impact if there were comments from affected interests regarding EO 12898 and the agency responded by indicating that the rule had a positive impact on EO 12898.

${ }^{6}$ We also spoke with multiple representatives of the EPA Region IX Office about the substance of rules with the purpose of ensuring that our coding of rules was correct. 
A second category is where rule language indicated explicitly that EO 12898 was considered but found to have no discernible EJ impact. For example, a rule on hazardous materials ("Hazardous waste management system...") indicates: "... EPA considered the impacts of this final rule on low-income populations and minority populations and concluded that the leachate management option selected by the Agency for this final rule would have no impact on nearby minority or low income populations" (64 FR 28, 1999: 3806).

The third category of agency utilisation is where EO 12898 is cited, but the citation is only pro forma - indicating the order is not relevant to the rulemaking. Pro forma citations tend to follow some variant of the following language: This action ("Dicamba; pesticide tolerance") does not "require any special considerations of environmental justice related issues as required by Executive Order 12898 ..." (64 FR 3, 1999: 759). Each of these statements is simply declarative; no additional evidence nor elaboration is provided to explain why the order has no relevance. ${ }^{7}$ Pro forma citations also include rules where commenters (during the notice and comment process) inquired about EJ and the response indicated that such inquiries were not relevant to the rule's final content.

The distinction between the second and third categories is substantively important. Citations of no impact indicate that an agency actively investigated the EJ implications, but concluded there were none to be found. Those in the third category assert no relevance; no explicit evidence is presented to support the irrelevance assertion - nor is any indication made that EJ concerns were actively considered in rule development. Therefore, it is appropriate to consider these as simply pro forma citations. ${ }^{8}$

There are three additional categories to note. Agencies may not cite EO 12898 in any capacity if they deem it completely irrelevant. Substantively, this may seem identical to the pro forma category, but the two categories are different, as pro forma citations indicate that the rule-making action considered EO 12898, at least to cite its lack of relevance. The category of cases where EO 12898 is not cited in any way, shape or form, does not appear in our data set as we only collected data on rules in which EO 12898 was cited in some capacity. Thus, the raw number of rules also represents attention levels given to the EJ issue. Second, rules citing EO 12898 constitute revisions (technical corrections, minor language corrections or date corrections, technical amendments, etc.) to an existing rule, making

\footnotetext{
${ }^{7}$ Pro forma cases also include rules where commenters inquired about the role of EO 12898 and the agency responded by indicating that the rule was not relevant to the executive order.

${ }^{8}$ A large number of rules in which the agency has issued a pro forma citation deal with technical levels to be set for pesticide tolerance. These are largely technical rulings on pesticides and subsequently we have removed them from the analysis.
} 


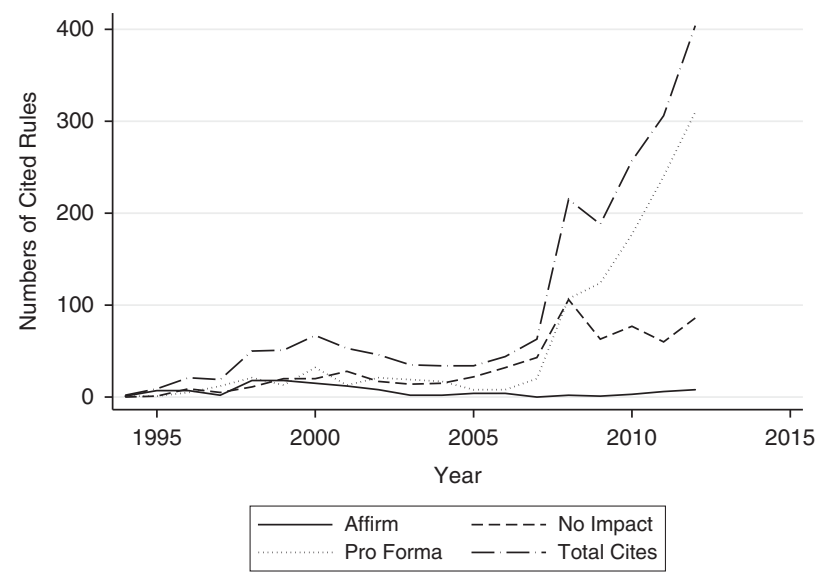

Figure 1 Citations of EO 12898, by type and year.

the citation redundant. As such, citations from this category were excluded from the final analysis. Finally, we ignored final rules where the only appearance of EO 12898 was in a comment and not in the rule itself.

Figure 1 provides a summary of the frequency of EO 12898 citations in final published rules by the three substantive categories, as well as the totals: affirmative citation, order considered but no EJ impact found and the pro forma no relevance declaration. The figure provides information on the substantive distinctions among citations and the pattern of citations over time. There is significant variation in the use of citations, but affirmative citations tend to be the most infrequently utilised category. The figure shows that affirmative citations were rare in the immediate wake of EO 12898's passage, but they slowly gathered steam, a development that should not be surprising given the ideological orientation of the Clinton Administration (1994-2000). The figure also reveals that cites as a whole increased between 1994 and 2000, showing increasing overall levels of attention to the issue of EJ, even if affirmative cites were a small percentage of the overall cites.

The number of affirmative cites remains fairly low throughout the Bush Administration, but the number of no impact cites gradually increases during Bush's second term, while pro forma cites slowly catch up. The rise in both types of cites suggests that bureaucrats under Bush employed a more risk averse approach in claiming environmental benefits, an observation that perhaps should not be surprising given the Bush Administration's reputation for avoiding strong environmental regulation (Provost et al. 2009). The 


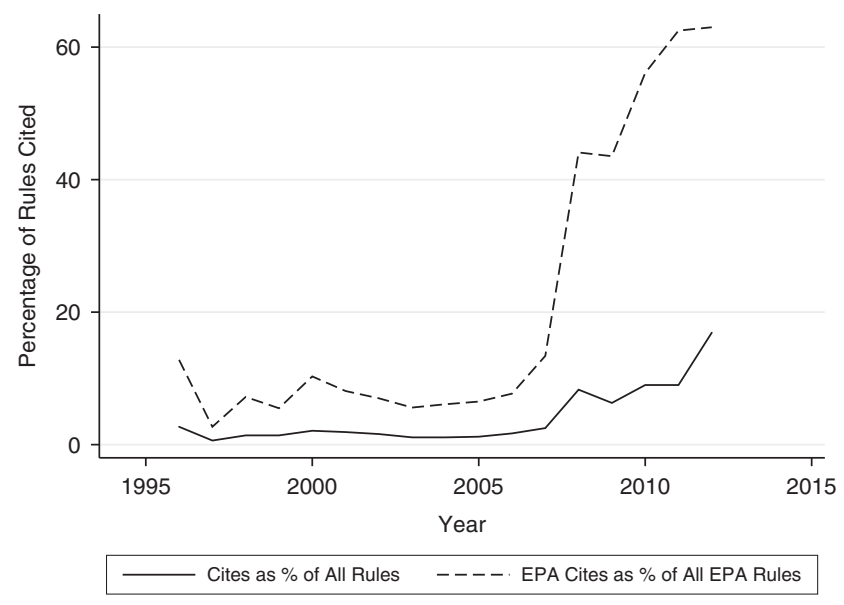

Figure 2 Proportion of total rules cited.

Administration took active steps to change the meaning of $\mathrm{EJ}$ in the context of EO 12898. A critical 2004 Office of Inspector General report summarised the change thusly: "the (EPA) changed the focus of the environmental justice program by de-emphasizing minority and low-income populations and emphasizing the concept of environmental justice for everyone" (US Office of Inspector General 2004).

Finally, the Obama Administration (2009-2012) patterns reveal a mixed picture. The overall number of EO 12898 cites is significantly larger than for either the Clinton or Bush Administrations, a level of attention that reflects the considerable resources poured into EJ during the Obama Administration. In 2011, the White House, the EPA and 16 other agencies restructured the Interagency Working Group and signed a memorandum of understanding, committing them to make EJ a priority, all as part of "Plan EJ 2014" (Kaswan 2013; Salcido 2016). However, despite the increased attention to EJ issues during Obama's first term, affirmative cites of EO 12898 do not appear with much more frequency than under Bush.

Figure 2 provides an additional look at the overall attention level to the EJ issue. Here we examine the total number of rules in which cites were made as a proportion of the total number of rules produced by all the agencies in question. Because $93 \%$ of the EO 12898 cites come from the EPA, we also examine the total number of EPA cites as a proportion of just the rules produced by the EPA. When we analyse cites as a proportion of rules from all agencies, we see a minor uptick in attention to EJ towards the 
Table 1. Citations of executive order 12898: by type and president

\begin{tabular}{lcccr}
\hline \hline $\begin{array}{l}\text { Presidential } \\
\text { Administration }\end{array}$ & $\begin{array}{c}\text { Affirmative } \\
\text { Citations }\end{array}$ & $\begin{array}{c}\text { No EJ Impact } \\
\text { Citations }\end{array}$ & $\begin{array}{c}\text { Pro Forma-No } \\
\text { Relevance Citations }\end{array}$ & Total \\
\hline Clinton & 74 & 66 & 86 & 226 \\
Bush & 28 & 281 & 218 & 527 \\
Obama & 18 & 282 & 845 & 1,145 \\
Totals & 120 & 629 & 1,149 & 1,898 \\
\hline \hline
\end{tabular}

Note: $\mathrm{EJ}=$ environmental justice.

end of the Clinton Administration, followed by a steady low level of attention in the Bush Administration until 2008. This attention continues to rise in the Obama Administration and remains at a higher equilibrium than under either Clinton or Bush. The data for both proportions reflect a similar trend. There is a small increase in the proportion of cites during the Clinton Administration, while the proportion remains reasonably constant during the Bush Administration. Towards the end of the Bush Administration and well into the Obama Administration, we see a significant increase in the attention paid towards EJ. Indeed, the percentages we observe during the Obama Administration reveal that all agencies, but particularly the EPA, were highly attuned to EJ issues within rulemaking.

Table 1 presents the citation data condensed by presidential administration, rather than by year and the same basic patterns are evident. These descriptive statistics show that agencies are responsive to political principals in the White House to a degree. One-third of the Clinton Administration's cites are affirmative. In total, 53\% of the Bush Administration's cites are of the "no EJ impact" variety compared with $29 \%$ under Clinton and $25 \%$ under Obama. Given the centrality of minority and low-income populations within the original EO, the Bush Administration's removal of that central emphasis appears to have made it easier to offer a cite of no impact in final rule-making actions.

For the Obama Administration, Table 1 reveals potential effects of both political control and policy-making uncertainty. Obama rules account for over half the cited rules in the data set, showing a high level of attention to the issue of EJ, as we might expect to see in a Democratic administration. However, only about $2 \%$ of these cites refer to EO 12898 in the affirmative fashion - evidence for the idea that uncertainties within the study and administration of EJ generate cites of no relevance or no impact, instead of bolder statements of positive impact. Finally, the number of rules for which no EJ impact was found is also higher in absolute numbers than under the 
other Administrations, although the proportion of no impact cites relative to total cites is smaller for Obama than for Clinton or Bush.

In order to test more rigorously the effects of political control and policymaking uncertainty, we conduct a multinomial logit analysis whereby we evaluate the effects of a number of predictor variables on the manner in which an agency cites EO 12898. The choices are the aforementioned categories whereby an agency affirmatively cites EO 12898, where an agency considers the rule's impact on EJ, but concludes no impact and finally, where EO 12898 is asserted to be not relevant at all. Multinomial logit is appropriate in this case because the dependent variable here takes on three possible outcomes, but the categories are discrete with no natural order (Greene 1997; Liao 1994). It is also important to note that multinomial logit only works under the assumption of the independence of irrelevant alternatives (IIA). That is, the introduction of a third category does not affect the relative probability of one of the other categories being chosen. Statistical tests are available for diagnosing the presence of IIA, but they have been deemed unreliable (Long and Freese 2014). Long and Freese also argue that multinomial logit works properly when the dependent variable alternatives are different and clearly distinguished. In our case, affirmative cites are clearly different from findings of "considered, but no impact" and "not relevant". The latter two categories are more similar, but there are still important differences as the processes used to reach the decisions are quite different. In pro forma cases, EJ is considered irrelevant, while in no impact cases, the agency carefully considers the impact and decides there is none. Thus, we maintain that each of our dependent variable categories are substantively different and should not present a problem for the IIA assumption.

Among the main predictor variables we include in our model, there are dummy variables for each of the three presidential administrations with the Clinton Administration acting as the baseline. To assess the effects of responsiveness to fire alarm oversight, we include a count of complaints filed under Title VI of the Civil Rights Act. Two important caveats are important to note. First, only complaints investigated by the EPA are available. While the exclusion of other agencies represents a measurement limitation, this likely does not present any serious deficiency in accounting for annual complaint activity, as $93 \%$ of the rules in our data set are crafted by the EPA. Second, there is ample reason for environmental activists to take a sceptical stance towards Title VI, as a large majority of the complaints ultimately go nowhere (Konisky 2016). However, there are few other reliable and similar measures of fire alarm oversight. And more importantly, far from seeing a declining pattern of use, as one might expect, our data show that the submission of Title VI complaints remains relatively stable over time, or at least does not precipitously decline. The standard 
Table 2. Variables and descriptive statistics

\begin{tabular}{|c|c|c|c|c|}
\hline Variables & $N$ & Mean & SD & Range/Values \\
\hline Citation of rule impact on EJ & 1,898 & 2.542 & 0.612 & $\begin{array}{l}1=\text { Affirmative cite } \\
2=\text { EJ not relevant } \\
3=\text { Pro forma/EJ not considered }\end{array}$ \\
\hline Clinton Administration & 1,898 & 0.120 & 0.324 & $\begin{array}{l}1=\text { Clinton Administration } \\
0=\text { Other administration }\end{array}$ \\
\hline Bush Administration & 1,898 & 0.278 & 0.448 & $\begin{array}{l}1=\text { Bush Administration } \\
0=\text { Other administration }\end{array}$ \\
\hline Obama Administration & 1,898 & 0.603 & 0.489 & $\begin{array}{l}1=\text { Obama Administration } \\
0=\text { Other administration }\end{array}$ \\
\hline House ideology & 1,898 & 0.138 & 0.057 & -0.026 to 0.208 \\
\hline Election year & 1,898 & 0.382 & 0.486 & $\begin{array}{l}1=\text { Election year } \\
0=\text { Not an election year }\end{array}$ \\
\hline Title VI complaints & 1,898 & 15.028 & 5.632 & $4-28$ \\
\hline Lagged $\%$ change in GDP & 1,898 & 1.490 & 2.094 & -2.8 to 4.7 \\
\hline $\begin{array}{l}\text { Annual tons } \mathrm{SO}_{2} \text { and } \mathrm{NO}_{2} \\
\text { emissions }\end{array}$ & 1,898 & $2,646.20$ & 768.228 & $1,885-4,669.6$ \\
\hline Air rule & 1,898 & 0.695 & 0.460 & $\begin{array}{l}1=\text { Air rule } \\
0=\text { Other type of rule }\end{array}$ \\
\hline Water rule & 1,898 & 0.044 & 0.206 & $\begin{array}{l}1=\text { Water rule } \\
0=\text { Other type of rule }\end{array}$ \\
\hline Hazardous waste rule & 1,898 & 0.091 & 0.287 & $\begin{array}{l}1=\text { Hazardous waste rule } \\
0=\text { Other type of rule }\end{array}$ \\
\hline Pesticide rule & 1,898 & 0.090 & 0.286 & $\begin{array}{l}1=\text { Pesticide rule } \\
0=\text { Other type of rule }\end{array}$ \\
\hline Emergency/disaster rule & 1,898 & 0.017 & 0.131 & $\begin{array}{l}1=\text { Emergency/disaster } \\
\text { planning rule } \\
0=\text { Other type of rule }\end{array}$ \\
\hline Economy/planning rule & 1,898 & 0.035 & 0.183 & $\begin{array}{l}1=\text { Economic/planning rule } \\
0=\text { Other type of rule }\end{array}$ \\
\hline $\begin{array}{l}\text { Internal Agency Procedure } \\
\text { Rule }\end{array}$ & 1,898 & 0.026 & 0.160 & $\begin{array}{l}1=\text { Agency procedure rule } \\
0=\text { Other type of rule }\end{array}$ \\
\hline Counter & 1,898 & 12.961 & 4.431 & $0-17$ \\
\hline
\end{tabular}

Note: $\mathrm{EJ}=$ environmental justice; GDP = gross domestic product.

deviation (see Table 2) reveals that there are annual spikes both upwards and downwards, but overall, there is no downward trend. We lag this variable by one year so that rule-making citations are potentially affected by the number of Title VI complaints from the previous year. We create interaction terms in which we evaluate whether there is greater responsiveness to fire alarm oversight during particular administrations. Thus, we examine the effect of Title VI complaints for each of the three presidencies.

In addition to the substantive policy area variables, we include three control variables. First, Congress's role in overseeing the bureaucracy is 
well-established and as we previously pointed out, congressional legislators also play an important role in facilitating fire alarm oversight. Specifically, legislators may be receptive to complaints from interest groups regarding bureaucratic behaviour (McCubbins and Schwartz 1984; McCubbins et al. 1987, 1989; Balla and Wright 2001). Thus, we include the Poole-Rosenthal measures of ideology of members of the House of Representatives, with the expectation that a more conservative House of Representatives leads to fewer affirmative cites of EO 12898. We also measure the effect of environmental quality by including a national measure of the annual tons of $\mathrm{NO}_{2}$ and $\mathrm{SO}_{2}$ emissions. Greater overall concentrations of air pollution may exacerbate the effects of environmental inequity leading rulemakers to think differently about how they cite EO 12898. Moreover, because economic activity can have similarly aggravating impacts on pollution levels, we measure the economy's impact on citations in rulemaking by including the lagged, annual percentage change in gross domestic product (GDP), measured in 2009 chained dollars.

Finally, we also control for policy issue area. We divide the substantive issues into seven categories: air quality, surface and drinking water, hazardous waste, pesticides, planning (land use, transportation and housing rules), emergency or disaster, and internal agency procedures. ${ }^{9}$ Internal procedure rules represent the baseline category in the analysis. Such variables help us to understand how our hypotheses apply across different environmental policy areas. For example, planning and emergency management rules are dealt with by agencies other than EPA, such as the Department of Transportation and Federal Emergency Management Administration (FEMA). EJ is not as strong a component of the mission for these agencies and consequently, we would expect to see fewer rules citing EO 12898 in these areas. Summary statistics for all predictor variables can be found in Table 2 .

The results of our analysis appear in Table 3. The multinomial logit analysis treats the third category - where EJ issues were deemed to be irrelevant and therefore pro forma - as the baseline category. As a result, we present the results for affirmative cites of EO 12898, as well as no impact cites - those instances in which EO 12898 was considered but deemed to have no impact. Additionally, we present two sets of results for these cites - with and without the interaction terms between presidential administration and Title VI complaints. Thus, in the first set of results, we analyse the effects of the presidency and Title VI complaints separately,

\footnotetext{
${ }^{9}$ These different types of rules are issued by a number of different agencies within our analysis, although we should point out that the overwhelming majority of rules are produced by the EPA. The other issuing agencies are those listed in footnote 1.
} 
Table 3. Multinomial logit analysis of executive order 12898 citations

\begin{tabular}{|c|c|c|c|c|}
\hline Independent Variables & Affirmative Impact & No EJ Impact & Affirmative Impact & No EJ Impact \\
\hline Bush Administration & $-1.211(0.704)^{*}$ & $0.946(0.460)^{* * *}$ & $-4.076(2.093)^{*}$ & $-3.229(1.098)^{* * * *}$ \\
\hline Obama Administration & $-3.371(1.549)^{* *}$ & $-0.465(0.683)$ & $-2.158(1.935)$ & $-1.639(0.846)^{*}$ \\
\hline House ideology & $19.834(6.998) * * *$ & $-9.320(2.472) * * *$ & $35.964(10.285)^{* * *}$ & $-3.637(3.101)$ \\
\hline Election year & $-0.950(0.313)^{* * *}$ & $-0.454(0.186)^{* *}$ & $-1.231(0.354) * * *$ & $-0.267(0.232)$ \\
\hline Title VI complaints & $0.033(0.026)$ & $-0.021(0.014)$ & $0.070(0.033)^{* * *}$ & $-0.041(0.024)^{*}$ \\
\hline Lagged $\%$ change in GDP & $-0.299(0.201)$ & $0.228(0.074) * * *$ & $-0.616(0.288)^{* *}$ & $0.033(0.086)$ \\
\hline Annual tons $\mathrm{SO}_{2}$ and $\mathrm{NO}_{2}$ emissions & $-0.001(0.001)$ & $-0.002(0.001)^{* *}$ & $-0.000(0.002)$ & $0.000(0.001)$ \\
\hline Air rule & $-0.193(0.524)$ & $-1.616(0.357) * * *$ & $-0.184(0.527)$ & $-1.665(0.362)^{* * * *}$ \\
\hline Water rule & $1.030(0.575)^{*}$ & $0.016(0.434)$ & $0.990(0.579) *$ & $-0.003(0.440)$ \\
\hline Hazardous waste rule & $-0.056(0.547)$ & $0.491(0.383)$ & $-0.031(0.549)$ & $0.494(0.388)$ \\
\hline Pesticide rule & $-0.789(0.531)$ & $-1.167(0.379) * * *$ & $-0.815(0.538)$ & $-1.314(0.386)^{* * * *}$ \\
\hline Emergency/disaster rule & $-0.225(0.894)$ & $1.051(0.601)^{*}$ & $0.274(0.901)$ & $-1.141(0.608)^{*}$ \\
\hline Economy/planning rule & $0.204(0.674)$ & $-0.328(0.438)$ & $0.178(0.678)$ & $0.404(0.443)$ \\
\hline Counter & $-0.434(0.189)^{*}$ & $-0.118(0.144)$ & $-0.357(0.238)$ & $-0.215(0.181)$ \\
\hline Bush $\times$ Title VI & & & $0.147(0.099)$ & $-0.226(0.053)^{* * * *}$ \\
\hline Obama $\times$ Title VI & & & $-0.147(0.060)^{* * *}$ & $-0.016(0.033)$ \\
\hline \multirow[t]{2}{*}{ Constant } & $-5.849(5.843)$ & $8.073(4.001)^{*}$ & $0.758(7.597)$ & $1.312(4.895)$ \\
\hline & \multicolumn{2}{|c|}{$\begin{array}{c}N: 1,898 \\
\text { Pseudo } R^{2}: 0.182\end{array}$} & \multicolumn{2}{|c|}{$\begin{array}{c}N: 1,898 \\
\text { Pseudo } R^{2}: 0.192\end{array}$} \\
\hline
\end{tabular}

Note: Numbers are multinomial logit coefficients with standard errors in parentheses.

Baseline category are Pro Forma cites in which EJ is not considered.

$\mathrm{EJ}=$ environmental justice; GDP $=$ gross domestic product. 
providing tests of Hypotheses 1 and $2 \mathrm{a}$. In the second set of results, we utilise interaction terms to test Hypothesis $2 \mathrm{~b}$ that the effect of Title VI increases the probability of affirmative cites, but only during Democratic administrations. In both models, support for Hypothesis 3 is given through a negative effect of Title VI complaints on affirmative cites, with and without interaction terms.

Our first analysis - without interaction terms - provides some support for Hypothesis 1, that there is presidential influence over the direction of cites. As the Clinton Administration provides the baseline case (and pro forma cites the baseline category in the dependent variable), we see that both Bush and Obama agencies are significantly less likely than Clinton agencies to affirmatively cite EO 12898. In this model, fire alarm oversight does not affect affirmative cites, as the coefficient for Title VI complaints is insignificant. A significant, yet counter-intuitive effect also appears for Congress, as agencies cite more affirmatively when the House of Representatives gets more conservative. However, it is not clear how strongly these factors are related and whether the correlation is coincidental. For example, the Republican Congress took over in 1995, as the Clinton Administration agencies began to affirmatively cite 12898 more aggressively.

With respect to control variables, only two show a significant effect in driving affirmative cites, compared with pro forma cites. In election years, rulemakers are less likely to affirmatively cite EO 12898 than in nonelection years. Amongst the policy area variables, water pollution rules appear far less frequently in the data set (mean $=0.044)$, but they are also significantly more likely to generate an affirmative cite $(\mathrm{p}<0.10)$. Finally, the counter variable which simply increases linearly with each passing year in the data set, is significant $(\mathrm{p}<0.10)$ and negative, which means that there is a gradual decaying effect in the use of affirmative cites.

Our primary interest is in the determinants of affirmative cites of EO 12898, but we also consider the circumstances under which agencies decide that the content of a rule will have no impact on EJ. In this model, Bush agencies are significantly more likely to cite rules as having no impact than as pro forma, while there are no significant effects for Obama agencies. A more conservative House of Representatives coincides with fewer no impact cites, as does the presence of election years. The negative election year coefficients for both affirmative and no impact cites means that pro forma cites are the likeliest of the three categories to be cited during election years. This is a possible indicator that agencies are risk averse during election years and do not want to make positive or negative cites for which they will be held accountable later. Additionally, as GDP changes in the previous year, rulemakers are more likely to cite rules as having no EJ impact, but increases in pollution are less likely to lead to cites of no EJ impact. Air and 

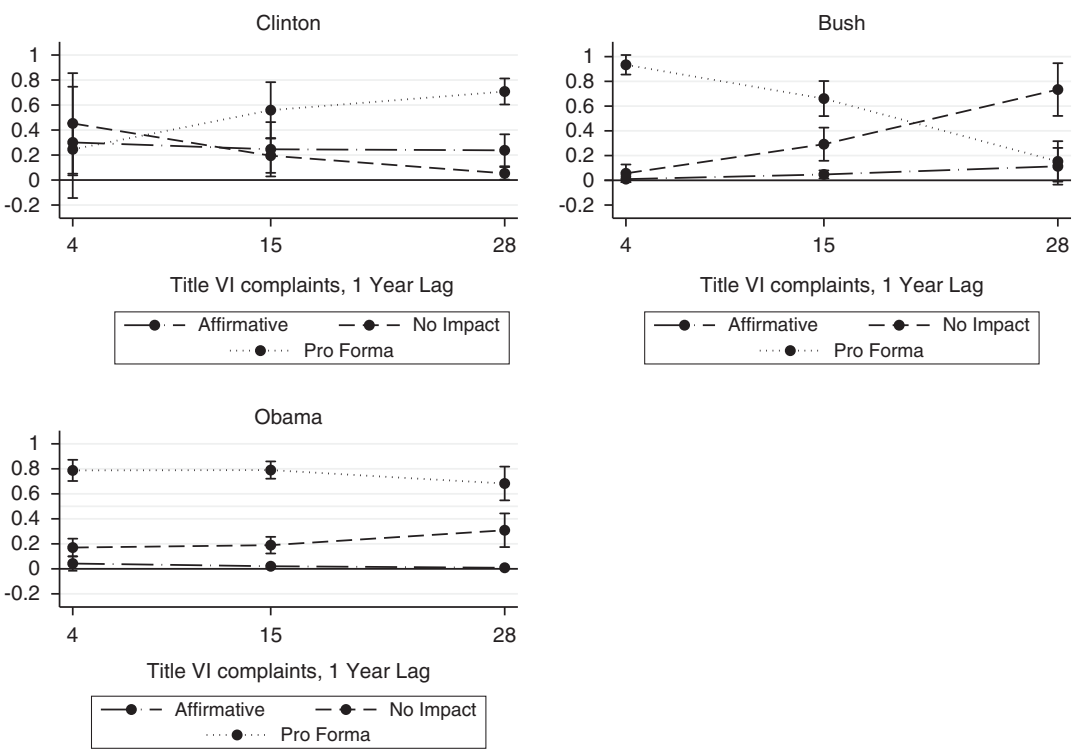

Figure 3 Predicted cites for each President, across title VI complaints.

pesticide rules are both less likely to lead to cites of no EJ impact, which is somewhat unsurprising, given how many pro forma cites these types of rules generate. Emergency and disaster management rules are more likely to lead to a ruling of no EJ impact $(\mathrm{p}<0.10)$, which indicates that rulemakers within FEMA can more confidently claim that their rules have no EJ impact on communities.

In the third and fourth columns of Table 3, we turn to the models with interaction terms - where we analyse the effect of Title VI complaints during different administrations on positive citations of EO 12898. Interpreting interaction term coefficients is more straightforward when they are converted into predicted probabilities and this is done in Figure 3.

Figure 3 uses the coefficients in columns 3 and 4 of Table 3 to provide the probability of each type of cite from each president, for the lowest, mean and highest values of Title VI complaints seen in the data set $(4,15$ and 28, respectively). ${ }^{10}$ Each figure represents the probabilities for one presidential administration. Continuous variables are set at their means and probabilities are calculated for air pollution rules, since they present a significant effect and comprise about $70 \%$ of the data set. As election years are also

10 The probabilities for the Clinton Administration are from the same model, but reestimated with the Bush Administration as the baseline presidency. 
significant, we derive probabilities for nonelection years, as they represent the majority of years in the data set.

The top-left figure within Figure 3 presents the probabilities of citation for the Clinton Administration. The probability of affirmative cites are significant for the mean and upper values of Title VI complaints. Although the overall probabilities are still below $25 \%$, they show a positive correlation with the number of Title VI complaints, illustrating some responsiveness through fire alarm oversight and providing support for Hypotheses 2 and 2a. Cites of no impact are significantly likely to happen $(0.45)$ when the number of Title VI complaints is low, but as the number of complaints increases, the probability of citing no impact drops considerably, to 0.19 and 0.05 , respectively, a trend that is also consistent with responsive fire alarm oversight. However, the results for Clinton also show that the probability of a pro forma cite rises significantly along with the number of Title VI complaints. The rise in these probabilities is also significantly larger than those for affirmative cites, thus illustrating the impact of uncertainty and risk aversion when citing EO 12898.

The top right figure in Figure 3 presents the probabilities of citation for the Bush Administration. The probability of an affirmative cite is low for all values of Title VI complaints and is only significant for the mean value. There are significant increases in probability of citing no impact $(0.29-0.73)$, as the number of Title VI complaints increases from mean to highest value. No impact cites in the Bush Administration are common, partly due to the president taking the emphasis off race and ethnicity within EO 12898, but these findings also suggest that no impact cites are a way of stemming the flow of Title VI complaints. The probability of citing pro forma is high when the number of Title VI complaints is low, but then decreases significantly as the number of Title VI complaints rises, possibly because cites of no impact are preferred when Title VI complaints reach higher levels.

Finally, the bottom left figure within Figure 3 presents the predicted probabilities for the Obama Administration. As with the Bush Administration, the probabilities of affirmative cites are low and only significant at the mean level of Title VI complaints. Obama agencies show other similarities to the Bush Administration as well, as Obama cites of no impact also increase along with Title VI complaints, although in much smaller increments. Perhaps the most distinguishing feature of the Obama Administration is the high prevalence of pro forma cites across the board. Despite the increasing trend in no impact cites, Obama rulemakers are always most likely to cite as pro forma.

\section{Discussion and conclusion}

In this analysis, we hypothesised that presidential ideology would affect the nature of bureaucratic utilisation of an EO, a key administrative 
policy-making tool employed by all presidents. Furthermore, how each administration cites EO 12898 and how each administration responds to fire alarm oversight in the form of Civil Rights Act Title VI complaints should vary. However, we also hypothesised that factors of policy-making uncertainty work against these factors of political control. Specifically, the difficulties of measuring regulatory benefits, coupled with scientific and procedural uncertainty, likely causes administrators to be risk averse and affirmatively cite EO 12898 less often. Our argument posited that Title VI complaints leading to fewer affirmative cites of EO 12898 would provide support for the policy-making uncertainty hypothesis.

The results presented provide support for each hypothesis, showing that partisan control of the presidency influences the use of EOs while policymaking uncertainty is also evident. In the first model (without interaction terms), Bush agencies were much less likely to affirmatively cite EO 12898 , but were more likely to cite EO 12898 as having no EJ impact. This is consistent with administrative actions taken under the Bush Administration in order to downplay the significance of race and ethnicity in rulemaking. Although our data do not cover the Trump Administration, we would expect similar no impact cite patterns from his administration and from most other would-be Republican administrations. Additionally, it is reasonable to expect that overall cites in the Trump Administration will also decrease considerably from the high levels observed in the Obama Administration, as the attention paid to EJ issues wanes considerably under Trump and EPA Administrator Scott Pruitt.

The different effects across the Clinton and Obama Administrations illustrate the uneven effects of political control in complex policy-making areas. Clinton agencies were more likely to cite EO 12898 affirmatively than either Bush or Obama agencies, but at the same time, we do find that Obama agencies paid the most attention to the EJ issue, as they overwhelmingly account for the largest proportion of cites, in a considerably smaller time frame than either of the other two administrations (four years versus seven and eight years, respectively). This fact was reflected in both the total number of cites from the Obama Administration, as well as the cites as a proportion of total rules published. While most of these Obama cites are pro forma, the raw number of no impact cites is larger than either Clinton or Bush's no impact cite tally. This shows that, although Obama agencies issued affirmative cites infrequently, they did pay attention to the issue of EJ, especially on the question of whether rules make existing inequitable situations worse. This interpretation is consistent with Banzhaf's observations: "EPA has tended to stop at perfunctory ... assertions that it is not creating or exacerbating an environmental injustice" (2011-2012, 5-6). 
The filing of Title VI complaints - our measure of fire alarm oversight conditions the effects of presidential ideology. The fact that the resolution of Title VI complaints has been neither swift (Konisky 2016) nor completely fair (Konisky and Teodoro 2016), raises questions about the effectiveness of fire alarm oversight. Affirmative cites are unlikely to occur in both the Bush and Obama Administrations, regardless of the number of Title VI complaints. The evidence suggests greater fire alarm responsiveness from the Clinton Administration, but even here Clinton rulemakers are far more likely to cite a rule as pro forma than as affirmative for high values of Title VI complaints. The probability of pro forma cites for Obama agencies is also high for all values of Title VI complaints, suggesting that for both Clinton and Obama agencies, pro forma cites might be seen as a way to minimise the issue and therefore reduce subsequent numbers of Title VI complaints. Bush agencies take a slightly different approach, as the Title VI complaints have a significant declining effect on the probability of a pro forma cite. Instead, no impact cites are significantly more likely as Title VI complaints rise. Developments within the Trump Administration as of this writing also raise the question of whether there are efforts to discourage the use of fire alarm oversight and what the effects of such efforts would be. The EPA data on Title VI complaints we use in this article disappeared from the EPA website after Donald Trump became president, an example that follows a broader pattern of the Trump EPA making scientific data unavailable (Hiltzik 2017).

The small number of affirmative citations by the Obama Administration is a bit counter-intuitive, but a more qualitative reading of the existing evidence presents a fairly logical picture. First, although President Obama directed his agencies to pay full attention to the issue of EJ, there is evidence that implementation issues have beset EO 12898 from its beginnings in 1994. Whatever success there may have been implementing EO 12898 during the Clinton Administration, the Bush Administration reshaped the focus of the EO in agency rulemaking so that race and ethnicity were essentially downplayed. As a result, when the Inspector General (2004) reviewed the programme in 2004, their resultant report indicated that there was a lack of strategic objectives and that there was not adequate implementation guidance for regional administrators. Such uncertainty feeds back to the federal level and creates risk aversion among civil servants when deciding how to cite EOs. More recent work shows a pattern indicating that the EPA's Office of Civil Rights is unable to resolve complex, technical issues or to define the key point of "disparate impact" (Kaswan 2013). These developments run parallel to the pattern of Obama agencies creating rules that are pledged not to exacerbate existing situations, rather than significantly improving them (Banzhaf 2011-2012). Such is the key 
difference between an affirmative citation or a pro forma or no impact citation, as these patterns illustrate well the effects of policy-making uncertainty.

This interesting and somewhat counter-intuitive result under the Obama Administration points to another broader implication of our analysis: understanding how presidents affect complex policy challenges through use of EO. Scholars with an interest in the administrative presidency have tried to discern previously whether EOs are used to bypass Congress or to reinforce legislative victories, and how political conditions determine frequency of their use (Krause and Cohen 1997; Shull 1997; Deering and Maltzman 1999; Fisher 1999; Mayer 1999, 2001). We have gone beyond these questions to examine how EOs are implemented in complex policy areas. Our results indicate that there is bureaucratic responsiveness to EOs, but at the same time, the underlying complexity of some policy areas can interfere with this responsiveness. This suggests that presidents may need to consider carefully the implementation of a particular issue before crafting a related EO.

In conclusion, our study shows how presidential ideology and policymaking uncertainty combine to influence administrative outputs in a complex policy area, such as EJ. The findings presented here also raise interesting questions about how to move forward with research on EJ and policymaking more broadly. First, why does the resolution of Title VI complaints typically take such a long time? Is it due to implementation difficulties at the federal level, broad uncertainty at the local level or both? Second, to what extent does state implementation of $\mathrm{EJ}$ issues substitute for the efforts at the federal level? Since President Clinton wrote EO 12898 in 1994, a number of states have created their own offices which deal with the issue of EJ, so it is worth asking whether these agencies more successfully deal with the complexities of local geography, business and community. Finally, with respect to EOs more broadly, our study raises the question of their durability and efficacy over time. EOs can be rewritten by subsequent administrations, but even those that survive are not immune to the trials and tribulations of policy implementation. Our study calls for greater analysis of how EOs are implemented and the challenges encountered by federal agencies, including those dynamics relevant to state and local agency counterparts, in maintaining fidelity to the intended purpose of an order during its implementation.

\section{Acknowledgements}

Previous versions of this paper were presented at meetings of the Midwest Political Science Association, the Southern Political Science Association and the European Consortium of Political Research Conference on Regulatory Governance. We would like to thank Neal Woods, David Nixon, Martino 
Maggetti, Fabrizio De Francesco, Jale Tosun, Fabrizio Gilardi and the three anonymous reviewers for helpful comments on this paper. Finally, we would like to thank Sojin Jang for her invaluable assistance with coding the data.

\section{References}

Anderton D., Anderson A., Oates J. M. and Fraser M. (1994) Environmental Equity: The Demographics of Dumping. Demography 31: 229-248.

Appelbaum B. (2011) As US Agencies Put More Value on a Life, Businesses Fret. New York Times, 16 February.

Balla S. (1998) Administrative Procedures and Political Control of the Bureaucracy. American Political Science Review 92: 663-673.

Balla S. and Wright J. (2001) Interest Groups, Advisory Committees and Congressional Control of the Bureaucracy. American Journal of Political Science 45: 799-812.

Banzhaf H. S. (2011-2012) Regulatory Impact Analyses of Environmental Justice Effects. Journal of Land Use 27: 1-31.

Been V. (1994) Locally Undesirable Land Uses in Minority Neighborhoods: Disproportionate Siting or Market Dynamics? Yale Law Journal 103: 1383-1422.

Been V. (1995) Analyzing Evidence of Environmental Justice. Journal of Land Use and Environmental Law 11: 1-36.

Bowen W. M. and Wells M. V. (2002) The Politics and Reality of Environmental Justice: A History and Considerations for Public Administrators and Policy Makers. Public Administration Review 62: 688-698.

Bullard R. (1990) Dumping in Dixie: Race, Class, and Environmental Quality. Boulder, CO: Westview Press.

Bullard R. (ed.) (1993) Confronting Environmental Racism: Views from the Grassroots. Boston, MA: South End Press.

Burwell D. and Luke W. C. (2007) Environmental Justice Comes Full Circle: Warren County Before and After. Golden Gate University Environmental Law Journal 1 (January): 9-32.

Carpenter D. P. (2002) Groups, the Media, Agency Waiting Costs, and FDA Drug Approval. American Journal of Political Science 46: 490-505.

Carpenter D. P. (2004) Protection Without Capture: Product Approval by a Politically Responsive, Learning Regulator. American Political Science Review 98: 613-631.

Cooper P. J. (1986) By Order of the President: Administration by Executive Order and Proclamation. Administration and Society 18: 233-262.

Cooper P. J. (2002) By Order of the President: The Use and Abuse of Executive Direct Action. Lawrence, KS: University of Kansas Press.

Cutter S. L. (1995) Race, Class and Environmental Justice. Progress in Human Geography 19(1): 111-122.

Cutter S. L., Holm D. and Clark L. (1996) The Role of Geographic Scale in Monitoring Environmental Justice. Risk Analysis 16(4): 517-526.

Deering C. J. and Maltzman F. (1999) The Politics of Executive Orders: Legislative Constraints on Presidential Power. Political Research Quarterly 52: 767-783.

Fisher L. (1999) Executive Orders and Proclamations, 1993-1999: Controversies with Congress and the Courts. Washington, DC: Congressional Research Service.

Goldman B. (1993) Not Just Prosperity: Achieving Sustainability with Environmental Justice. Washington, DC: National Wildlife Federation.

Goldman B. and Fitton L. (1994) Toxic Wastes and Race Revisited. Washington, DC: Center for Policy Alternatives. 
Grant D., Trautner M. N., Downey L. and Thiebaud L. (2010) Bringing the Politics Back In: Environmental Inequality and the Organization of Chemical Production. American Sociological Review 75: 479-504.

Greene W. H. (1997) Econometric Analysis. Upper Saddle River, NJ: Prentice Hall.

Hiltzik M. (2017) Trump's EPA Has Started to Scrub Climate Change Data from its Website, Los Angeles Times, 1 May, http://www.latimes.com/business/hiltzik/la-fi-hiltzik-epaclimate-20170501-story.html (accessed 19 December 2017).

Kaswan A. (2013) Environmental Justice and Environmental Law. Fordham Environmental Law Review 24: 149-179.

Kerwin C. M. (2003) Rulemaking: How Government Agencies Write Law and Make Policy, 3rd ed. Washington, DC: Congressional Quarterly Press.

Konisky D. (2009a) Inequities in Enforcement? Environmental Justice and Government Performance. Journal of Policy Analysis and Management 28: 102-121.

Konisky D. (2009b) The Limited Effects of Federal Environmental Justice Policy on State Enforcement. Policy Studies Journal 37: 475-496.

Konisky D. (2015) The Federal Government's Response to Environmental Inequality. In D. Konisky (ed.), Failed Promises: Evaluating the Federal Government's Response to Environmental Justice. Cambridge: MIT Press, 29-56.

Konisky D. (2016) Environmental Justice Delayed: Failed Promises, Hope for the Future. Environment: Science and Policy for Sustainable Development 58(2): 4-15.

Konisky D. and Teodoro M. (2016) When Governments Regulate Governments. American Journal of Political Science 60: 559-574.

Krause G. A. and Cohen D. B. (1997) Presidential Use of Executive Orders, 1953-1994. American Politics Quarterly 25: 458-471.

Lewis D. E. (2005) Staffing Alone: Unilateral Presidential Action and the Politicization of the Executive Office of the President, 1988-2004. Presidential Studies Quarterly 35: 496-514.

Lewis D. E. (2008) The Politics of Presidential Appointments: Political Control and Bureaucratic Performance. Princeton, NJ: Princeton University Press.

Lewis D. E. (2009) Personnel is Policy: George W. Bush's Managerial Presidency. In C. Provost and P. Teske (eds), President George W. Bush's Influence Over Bureaucracy and Policy: Extraordinary Times, Extraordinary Powers. New York: Palgrave Macmillan, 19-40.

Liao T. F. (1994) Interpreting Probability Models: Logit, Probit, and other Generalized Linear Models. Thousand Oaks, CA: Sage Publications.

Long J. S. and Freese J. (2014) Regression Models for Categorical Dependent Variables Using Stata, 3rd ed. College Station, TX: Stata Press.

Maguire K. and Sheriff G. (2011) Comparing Distributions of Environmental Outcomes for Regulatory Environmental Justice Analysis. International Journal of Environmental Research and Public Health 8: 1707-1726.

Maor M. (2007) A Scientific Standard and An Agency's Independence: Which of These Reputation Protection Mechanisms is Less Susceptible to Political Moves? Public Administration 85(4): 961-978.

Mayer K. R. (1999) Executive Orders and Presidential Power. Journal of Politics 61: 445-466.

Mayer K. R. (2001) With the Stroke of a Pen: Executive Orders and Presidential Power. Princeton, NJ: Princeton University Press.

McCubbins M. D., Noll R. and Weingast B. (1987) Administrative Procedures as Instruments of Political Control. Journal of Law, Economics and Organization 3: 243-277.

McCubbins M. D., Noll R. and Weingast B. (1989) Structure and Process as Solutions to the Politicians Principal-Agency Problem. Virginia Law Review 74: 431-482. 
McCubbins M. D. and Schwartz T (1984) Congressional Oversight Overlooked: Police Patrols Versus Fire Alarms. American Journal of Political Science 28(1): 165-179.

McGarity T.O. (1991) Reinventing Rationality: The Role of Regulatory Analysis in the Federal Bureaucracy. Cambridge: Cambridge University Press.

Mitchell J. T., Thomas D. S. K. and Cutter S. L. (1999) Dumping in Dixie Revisited: The Evolution of Environmental Injustices in South Carolina. Social Science Quarterly 80(2): 229-243.

Moe T. (1985) Control and Feedback in Economic Regulation: The Case of the NLRB. American Political Science Review 79: 1094-1116.

Moe T. (1987) An Assessment of the Positive Theory of "Congressional Dominance". Legislative Studies Quarterly 12: 475-520.

Mohai P. and Bryant B. (1992) Environmental Racism. In Mohai P. and Bryant B. (eds.), Race and the Incidence of Environmental Hazards, Bryant and Mohai. Boulder, CO: Westview Press, 163-176.

Nathan R. (1983) The Administrative Presidency. New York: Wiley.

Noonan D. (2008) Evidence of Environmental Justice: A Critical Perspective on the Practice of EJ Research and Lessons for Policy Design. Social Science Quarterly 89(5): 1153-1174.

Noonan D. (2015) Assessing the EPA's Experience With Equity in Standard Setting. In David Konisky (ed.), Failed Promises: Evaluating the Federal Government's Response to Environmental Justice. Cambridge: MIT Press, 85-116.

Oakes J., Anderton D. and Anderson A. (1996) A Longitudinal Analysis of Environmental Equity in Communities With Hazardous Waste Facilities. Social Science Research 25: 125-148.

O’Neil S. G. (2007) Superfund: Evaluating the Impact of Executive Order 12898. Environmental Health Perspectives 115: 1087-1093.

Potoski M. (1999) Managing Uncertainty Through Bureaucratic Design: Administrative Procedures and State Air Pollution Control Agencies. Journal of Public Administration Research and Theory 9(October): 623-640.

Potoski M. and Neal W. (2001) Designing State Clean Air Agencies: Administrative Procedures and Bureaucratic Autonomy. Journal of Public Administration Research and Theory 11 (April): 203-222.

Provost C., Gerber B. and Pickup M (2009) Flying Under the Radar? Political Control and Bureaucratic Resistance in the Bush EPA. In C. Provost and P. Teske (eds.), President George W. Bush's Influence Over Bureaucracy and Policy: Extraordinary Times, Extraordinary Powers. New York: Palgrave Macmillan, 169-186.

Ringquist E. J. (1997) Equity and the Distribution of Environmental Risk. Social Science Quarterly 78: 811-829.

Ringquist E. J. (2005) Assessing Evidence of Environmental Inequities: A Meta Analysis. Journal of Policy Analysis and Management 24: 223-247.

Salcido R. E. (2016) Reviving the Environmental Justice Agenda. Chicago-Kent Law Review 91: $115-137$.

Sapat A., Vos J. J. and Thai K. V. (2002) Environmental Injustice: An Emerging Public Policy Issue. International Journal of Public Administration 25: 143-168.

Shadbegian R. and Wolverton A. (2015) Evaluating Environmental Justice: Analytic Lessons from the Academic Literature and in Practice. In D. Konisky (ed.), Failed Promises: Evaluating the Federal Government's Response to Environmental Justice. Cambridge: MIT Press, 117-142.

Shull S. A. (1997) Presidential-Congressional Relations: Policy and Time Approaches. Ann Arbor, MI: University of Michigan Press.

Spence D. (1997) Administrative Law and Agency Policymaking: Rethinking the Positive Theory of Political Control. Yale Journal of Regulation 14: 406-450. 
Spence D. (1999) Agency Discretion and the Dynamics of Procedural Reform. Public Administration Review 59: 425-458.

United Church of Christ Commission for Racial Justice (1987) Toxic Wastes and Race in the United States. New York: United Church of Christ and Public Data Access Inc.

United States General Accounting Office (US GAO) (1983) Siting of Hazardous Waste Landfills and their Correlation With Racial and Economic Status of Surrounding Communities. Washington, DC: Government Printing Office.

United States General Accounting Office (US GAO) (1995) Hazardous and Nonhazardous Waste: Demographics of People Living Near Waste Facilities. Washington, DC: Government Printing Office.

United States (US) Office of Inspector General (2004) EPA Needs to Consistently Implement the Intent of the Executive Order on Environmental Justice. 2004-P-00007. Washington, DC: Office of Inspector General.

United States General Accounting Office (2005) EPA Should Devote More Attention to Environmental Justice When Developing Clean Air Rules. GAO-05-289 Washington, DC: US GAO.

Wagner W. (2010) Administrative Law, Filter Failure and Information Capture. Duke Law Journal 59: 1321-1432.

Weingast B. R. and Moran M. J. (1983) Bureaucratic Discretion or Congressional Control? Regulatory Policymaking at the Federal Trade Commission. Journal of Political Economy 91: 765-800.

Whitford A. B. (2005) The Pursuit of Political Control by Multiple Principals. Journal of Politics 67: 28-49.

Whitford A. B. (2014) Information and Uncertainty in Policy Implementation: Evidence from the Implementation of EPA Waivers. Journal of Public Administration Research and Theory 24: 267-288.

Wood D. B. and Waterman R. W. (1994) Bureaucratic Dynamics: The Role of Bureaucracy in a Democracy. Boulder, CO: Westview Press.

Yackee S. W. and Yackee J. W. (2006) A Bias Towards Business? Assessing Interest Group Influence on the U.S. Bureaucracy. Journal of Politics 68: 128-139. 